\title{
Early menarche and childhood adversities in a nationally representative sample
}

\author{
Kimberly L Henrichs ${ }^{1}$, Heather L McCauley ${ }^{2,3}$, Elizabeth Miller ${ }^{2,3}$, Dennis M Styne ${ }^{4 *}$, Naomi Saito ${ }^{5}$ and Joshua Breslau ${ }^{6}$
}

\begin{abstract}
Background: Epidemiological evidence suggests that early menarche, defined as onset of menses at age 11 or earlier, has increased in prevalence in recent birth cohorts and is associated with multiple poor medical and mental health outcomes in adulthood. There is evidence that childhood adversities occurring prior to menarche contribute to early menarche.

Methods: Data collected in face-to-face interviews with a nationally representative sample of women age 18 and over $(\mathrm{N}=3288)$, as part of the National Comorbidity Survey-Replication, were analyzed. Associations between pre-menarchal childhood adversities and menarche at age 11 or earlier were estimated in discrete time survival models with statistical adjustment for age at interview, ethnicity, and body mass index. Adversities investigated included physical abuse, sexual abuse, neglect, biological father absence from the home, other parent loss, parent mental illness, parent substance abuse, parent criminality, inter-parental violence, serious physical illness in childhood, and family economic adversity.
\end{abstract}

Results: Mean age at menarche varied across decadal birth cohorts $\left(x^{2}{ }_{(4)}=21.41, p<.001\right)$ ranging from a high of 12.9 years in the oldest cohort (age 59 or older at the time of interview) to a low of 12.4 in the second youngest cohort (age 28-37). Childhood adversities were also more common in younger than older cohorts. Of the 11 childhood adversities, 5 were associated with menarche at age 11 or earlier, with OR of 1.3 or greater. Each of these five adversities is associated with a $26 \%$ increase in the odds of early menarche $(\mathrm{OR}=1.26,95 \% \mathrm{Cl} 1.14-1.39)$. The relationship between childhood sexual abuse and early menarche was sustained after adjustment for co-occurring adversities. ( $\mathrm{OR}=1.77,95 \% \mathrm{Cl} 1.21-2.6)$.

Conclusions: Evidence from this study is consistent with hypothesized physiological effects of early childhood family environment on endocrine development. Childhood sexual abuse is the adversity most strongly associated with early menarche. However, because of the complex way that childhood adversities cluster within families, the more generalized influence of highly dysfunctional family environments cannot be ruled out.

\section{Background}

Among industrialized nations, and the United States in particular, the average age of menarche has decreased over the past century [1-3]. This trend is of public health concern as early menarche, commonly defined as onset of menses before age 12, is associated with multiple poor health outcomes in adults from increased cardiovascular and metabolic diseases to breast cancer and all-cause mortality [4-6]. Early menarche has also been linked to increased health risk behaviors, earlier sexual debut, and depression [7-9].

\footnotetext{
* Correspondence: dennis.styne@ucdmc.ucdavis.edu

${ }^{4}$ University of California Davis, 2516 Stockton Blvd, Sacramento, CA 95817, USA

Full list of author information is available at the end of the article
}

Early menarche is likely the result of multiple influences on early endocrine development. Epidemiological studies have found that early menarche is associated with multiple inter-related social and environmental factors, including nutrition and obesity [10-12], genetic factors [13,14], and general health status [15], with differences noted by race/ethnicity and familial socioeconomic status [16-18]. Among social factors with potential influence on early menarche, a growing body of literature points to exposure to childhood adversities as a risk factor for early menarche, including childhood sexual abuse [9,19-34]. The adverse impacts of biological father absence and the presence of non-related males in the home have also been suggested, though the evidence remains mixed [26,35-41]. To the best of our knowledge, 
studies to date have not considered the effects of a broader range of related childhood adversities on menarche. As adversities tend to cluster together, identifying specific adversities associated with early menarche could help identify particular environmental influences on endocrine pathways, should they exist. Elucidating the types of adversities associated with early onset of menarche is critical not only for guiding research on the impact of stressors on neuroendocrine development but also informing the design of targeted interventions for children exposed to specific adversities and potentially mitigating the impact of early pubertal development. This study assesses the joint predictive effects on age of menarche of a broad range of childhood adversities, including absence of biological father in the home and childhood sexual abuse, utilizing a large nationally representative sample from the United States, the National Comorbidity Survey Replication (NCS-R).

\section{Methods \\ Sample}

The NCS-R is a multi-stage clustered area probability survey (respondents selected into the sample were clustered within selected geographic units [42]) representative of the adult (ages 18+), non-institutionalized, civilian, English speaking population of the continental US focused on the prevalence and correlates of mental disorders $[43,44]$. Non-clinician interviewers conducted computer assisted face-to-face structured interviews between February 2001 and April 2003. The NCS-R interview schedule was the version of the World Health Organization (WHO) Composite International Diagnostic Interview (CIDI) developed for the WHO World Mental Health Survey Initiative [38,44,45]. The Human Subjects Committees of both Harvard Medical School and the University of Michigan approved the NCS-R recruitment, consent and field procedures. All NCS-R data and documentation are publically available at http://www.icpsr.umich.edu/CPES.

All respondents $(\mathrm{N}=8098)$ completed a Part I core diagnostic interview. To reduce respondent burden, a subsample (selected with known probabilities) received a Part II interview, which included assessments of risk factors, consequences, services and other correlates of the core disorders. The Part II sample included all Part I respondents age 25 or younger, all Part I respondents meeting initial criteria for a mental disorder, and a random sample of Part I respondents over the age of 25 who did not meet criteria for a mental disorder. Sample weights accounted for differential probability of selection and non-response. Additional weights helped match demographic characteristics of the sample to those of the target population $[43,44]$. Of the 3,310 women completing the Part II interview, 22 provided no information on age at menarche and were excluded from the analysis, leaving a sample of 3288 women.

\section{Measures \\ Early menarche}

Age at menarche was the self-reported age at first menstrual period. Early menarche was defined as occurrence of menarche at 11 years of age or less, consistent with values equal to or less than the $25^{\text {th }}$ percentile for age as published from national estimates of menarche timing for non-Hispanic White U.S. girls in the National Health and Nutrition Examination Survey III (1988-1994) [46]. Missing values for age of menarche were imputed for 40 participants who did not recall their exact age using information from questions about whether their first period occurred about the same time as, earlier than, or much earlier than their peers. Ages were imputed using the average age intervals associated with these categories among the large majority of respondents who provided their exact age at menarche.

\section{Childhood adversities}

Eleven childhood adversities were included in the analyses - (1) physical abuse, (2) sexual abuse, (3) neglect, (4) biological father absence from the home, (5) other parent loss, (6) parent mental illness, (7) parent substance abuse, (8) parent criminality, (9) inter-parental violence, (10) serious physical illness in childhood, and (11) family economic adversity. Physical abuse and interparental violence were coded as moderate physical violence towards the respondent by the parent or adult caregiver or between parents or adult caregivers, respectively, using the revised Conflict Tactics Scale [47]. Sexual abuse was assessed with questions developed for the baseline National Comorbidity Survey about rape, sexual assault and molestation [48]. Neglect was assessed with a five-item scale developed for child welfare studies [49].

Absence of biological father was defined using a series of questions about respondents' family structure during childhood. Respondents were first asked whether they had lived their entire childhood up to age 16 with both biological parents in their household. Respondents who answered 'no' to this question were considered to have had an absent biological father if they had more than one adult male living in their household for at least six months during childhood, the male head of household for most of their childhood was not their biological father, their biological father died prior to their age at menarche, they lived in foster care or with an adoptive family, or they had no male head of household for most of their childhood.

Parent mental illness and substance use disorders were assessed using the family history research diagnostic 
criteria, for either male or female adult caregiver [50,51]. Parental criminality was assessed through questions about whether the respondent's parents were involved in criminal activities, arrested or sent to prison. Economic adversity was defined as having received welfare or not having a working parent as head of household. Information on the timing of parental death, divorce, separation, serious physical illness, inter-parental violence and sexual abuse was used to determine whether these childhood adversities began before the initiation of menstruation.

\section{Additional covariates}

Body mass index at time of interview was calculated from self-reported height and weight. Z-scores for variation in an individual's BMI (body mass index) from the mean of their birth cohort were calculated and used to adjust statistically for BMI, given the relative stability of BMI within cohorts over time [52,53]. Race-ethnic categories were defined as mutually exclusive categories based on self-report. Age groups were defined to produce five birth cohorts of approximately equal size.

\section{Statistical analysis}

Prevalence of early menarche was calculated as the proportion of respondents who reported that their first menstrual period occurred at 11 years of age or younger. Discrete time survival models with time-varying covariates were used to estimate associations of childhood adversities with early menarche. Survival models were adjusted statistically for age, race/ethnicity and BMI. Data were arranged by person-year (from age 6 to age 11 or age of menarche, whichever came first) with timevarying indicators for each childhood adversity. The survival models include one observation per year of age starting with age 6 . If a respondent reported an adversity occurring prior to age 6 , then that adversity was coded as present at age 6 (and all subsequent ages). Associations between childhood adversities and early menarche were calculated as adjusted odds ratios. Confidence intervals and statistical tests were calculated using the Taylor series linearization method as implemented in the SUDAAN software package to account for the complex sample design of the NCS-R [54]. Statistical significance was assessed using two-sided .05 level tests.

\section{Results}

\section{Sample characteristics and cohort variation in age at menarche and childhood adversities}

The mean age of the sample was 45.7 years $(\mathrm{se}=0.60) .72 \%$ were White, 13\% non-Hispanic Black, 10\% Hispanic, and $4 \%$ other race/ethnicity. Mean BMI was 27.

The mean age at menarche was highest (12.9 years) in the oldest birth cohort, those age 59 and over at the time of interview, but the decline was not monotonic across birth cohorts (Table 1). Variation in the prevalence of childhood adversities across birth cohorts follows a similar pattern. Just over half $(52.8 \%)$ of the eldest cohort reported no adversities in contrast to $38.2 \%$ of the youngest cohort (i.e. those ages 18-27). In particular, younger cohorts reported increased frequency of biological father absence $\left(x^{2}=84.01, p<0.001\right)$, a childhood adversity theorized to have a particularly strong connection to early menarche. The proportion of girls not living with their biological fathers was more than twice as high in youngest versus oldest birth cohorts. Childhood sexual abuse was reported with greater frequency among the two younger cohorts $\left(x^{2}=25.13, p<0.001\right)$. The 28-37 year old cohort reported the highest prevalence of early menarche (24.9\%, CI 21.3-28.8), the youngest mean age of menarche (12.4 years), the greatest exposure to adversities $(66.5 \%)$, and the highest prevalence of multiple cooccurring adversities.

Figure 1 shows the prevalence of early menarche across groups defined by the number of pre-menarchal childhood adversities. The prevalence of early menarche is close to $20 \%$ among people reporting no adversities, 1 or 2 adversities and 3 or 4 adversities. Elevated prevalence of early menarche is limited to the group with 5 or more adversities among whom it reaches $34 \%$.

\section{Associations of pre-menarchal childhood adversities with early menarche}

An initial set of models was specified to identify the adversities most strongly associated with early menarche, adjusting for age, ethnicity and BMI, but without adjustment for co-occurring adversities (Table 2). Of the 11 childhood adversities tested, only 4 were significantly associated with early menarche at the $\mathrm{p}=.05$ level. Odds ratios for these four adversities (physical abuse, sexual abuse, parental mental illness and family violence) ranged from 1.36 to 2.19 . The odds ratio associated with parental substance use was of similar magnitude, 1.3, but did not reach statistical significance (95\% CI 0.911.91). Absence of the biological father from the home was not associated with early menarche (OR $=1.0895 \%$ CI 0.86- 1.36).

The five childhood adversities most strongly associated with early menarche were entered into two models to determine the joint effects of co-occurring adversities on early menarche (Table 3 ). In the first model, a simple count of adversities was entered as a continuous variable, with statistical adjustment for age, ethnicity, and BMI. Each adversity was associated with a statistically significant $26 \%$ increase in the odds of early menarche. In the second model, to examine the relative impact of specific adversities on early menarche, all five adversities were entered as simultaneous predictors (main effects model), with no interactions among the adversities. All 
Table 1 Age of menarche, absence of bio-father, childhood sexual abuse (prior to menarche), and number of childhood adversities across birth cohorts

\begin{tabular}{|c|c|c|c|c|c|c|c|c|c|c|}
\hline \multirow[t]{3}{*}{ Age } & \multirow[b]{3}{*}{$\mathbf{N}$} & \multirow[t]{2}{*}{ AOM } & \multirow{3}{*}{$\begin{array}{c}\begin{array}{c}\text { Early } \\
\text { menarche }\end{array} \\
\%(n)\end{array}$} & \multirow{3}{*}{$\begin{array}{c}\begin{array}{c}\text { Not Lived } \\
\text { with Bio-father }\end{array} \\
\quad \%(n)\end{array}$} & \multirow{3}{*}{$\begin{array}{c}\text { Childhood } \\
\text { sexual } \\
\text { abuse } \\
\%(n)\end{array}$} & \multicolumn{4}{|c|}{ Number ACE } & \multirow{3}{*}{$\begin{array}{l}\text { Number } \\
\text { ACE } \\
\text { Mean (SD) }\end{array}$} \\
\hline & & & & & & 0 & 1,2 & 3,4 & $4<$ & \\
\hline & & Mean (SD) & & & & \multicolumn{4}{|c|}{$\%(n)$} & \\
\hline 18-27y/o & 654 & $12.5(1.57)$ & $20.2(158)$ & $37.1(243)$ & $15.8(133)$ & $38.2(221)$ & $40.2(266)$ & 15.4 (104) & $6.2(63)$ & $1.4(1.55)$ \\
\hline $28-37 y / 0$ & 655 & $12.4(1.31)$ & $24.9(163)$ & $33.4(206)$ & 18.7 (144) & $33.5(210)$ & $44.0(286)$ & $15.9(99)$ & $6.7(60)$ & $1.6(1.50)$ \\
\hline $38-47 y / 0$ & 697 & $12.7(1.62)$ & $20.4(152)$ & $21.1(149)$ & 14.8 (128) & 47.9 (290) & $40.0(281)$ & $8.1(80)$ & $4.2(46)$ & $1.0(1.36)$ \\
\hline $48-58 y / 0$ & 636 & $12.6(1.52)$ & $22.5(146)$ & 15.5 (112) & 14.8 (118) & 49.4 (276) & $37.0(249)$ & $9.1(73)$ & $5.0(38)$ & $1.1(1.42)$ \\
\hline 59-98y/o & 646 & $12.9(1.84)$ & 17.7 (126) & $16.2(104)$ & $7.3(57)$ & $52.8(331)$ & $38.6(250)$ & $7.6(52)$ & $0.9(13)$ & $0.8(1.21)$ \\
\hline Wald chi-square & & $x_{(4)}^{2}=21.41$ & $x^{2}{ }_{(4)}=9.43$ & $x_{(4)}^{2}=84.01$ & $x_{(4)}^{2}=25.13$ & \multicolumn{4}{|c|}{$x_{(12)}^{2}=123.62$} & $x^{2}(4)=46.46$ \\
\hline P-value & & $<0.001$ & 0.051 & $<0.001$ & $<0.001$ & \multicolumn{4}{|c|}{$<0.001$} & $<0.001$ \\
\hline
\end{tabular}

Birth cohorts divided by decade of birth; percentages are weighted.

$\mathrm{AOM}=$ age of menarche.

$\mathrm{ACE}=$ adverse childhood experiences.

odds ratios in the second model exceeded 1, but only sexual abuse reached statistical significance $(\mathrm{OR}=1.77$, 95\% CI 1.21-2.60). Tests of statistical interactions between co-occurring adversities, including tests for diffuse interactions, were not statistically significant. In addition, tests for statistical interactions between race/ ethnicity and childhood adversities were not statistically significant.

\section{Discussion}

Childhood adversities predict earlier onset of menarche in this large national sample of women, after statistical adjustment for BMI and race/ethnicity. The prevalence of early menarche is elevated at high levels of cooccurring adversities, specifically in the $5 \%$ of the population with more than five adversities. Among respondents reporting between one and four adversities (51\% of the sample), the prevalence of early menarche was not significantly higher than those reporting no adversities ( $44 \%$ of the sample).

While risk for early menarche appears to increase with a greater number of childhood adversities, the variable for the count of adversities (Model 1 in Table 3) imposes an assumption that each adversity is associated with an

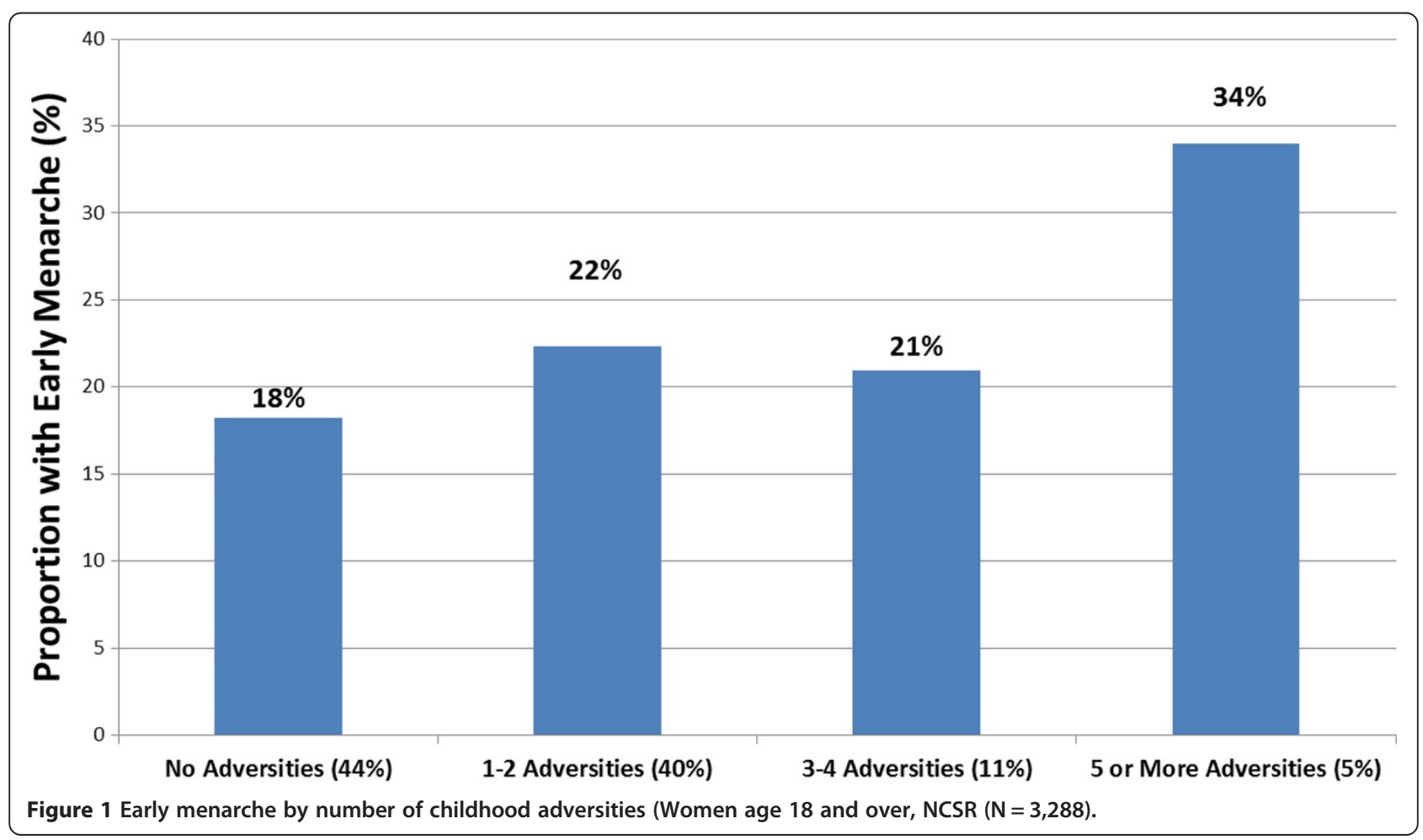


Table 2 Associations of individual adverse childhood experiences with early menarche

\begin{tabular}{cccc}
\hline & Odds ratio & $\mathbf{9 5 \%} \mathbf{C l}$ & Wald ChiSq \\
\hline Neglect & 1.03 & $(0.63,1.67)$ & 0.01 \\
Parent criminality & 1.05 & $(0.77,1.43)$ & 0.10 \\
Bio-father absent & 1.08 & $(0.86,1.36)$ & 0.48 \\
Physical illness & 1.08 & $(0.71,1.64)$ & 0.13 \\
Other parent loss & 1.15 & $(0.63,2.09)$ & 0.23 \\
Economic adversity & 1.23 & $(0.88,1.73)$ & 1.53 \\
Parent substance abuse & 1.30 & $(0.91,1.91)$ & 2.15 \\
Parent mental illness & 1.36 & $(1.08,1.71)$ & $7.32^{* *}$ \\
Family violence & 1.40 & $(1.03,1.89)$ & $4.97^{* * *}$ \\
Physical abuse & 1.81 & $(1.32,2.48)$ & $14.59^{*}$ \\
Sexual abuse & 2.19 & $(1.54,3.12)$ & $20.22^{*}$ \\
\hline
\end{tabular}

${ }^{*} \mathrm{p}<0.001 .{ }^{* *} \mathrm{p}<0.01$. $^{* * *} \mathrm{p}<0.05$.

Each odds ratio estimated in a separate model with statistical adjustment for age and race/ethnicity.

identical increase in the risk for early menarche. The $26 \%$ increase found with Model 1 is an average across all the adversities. Figure 1, in contrast, does not make this assumption. This apparent contradiction demonstrates the difficulty in selecting between different models of the association between adversities and early menarche. The findings appear to go against a simple, linear relationship and suggest that a threshold model is a better fit to the overall pattern in the data. That is, risk for early menarche appears to increase above a certain number of adversities.

These analyses were also designed to identify contributions of specific childhood adversities on early menarche (Model 2 in Table 3); findings are consistent with the suggestion in the literature that childhood sexual abuse is associated with earlier onset of menarche. As observational studies have limited ability to distinguish between effects of specific adversities and more generalized effects of childhood environment in the context of highly clustered adversities, this study included a much broader range of childhood adversities than prior studies. Specifically, of the 11 adversities, childhood sexual abuse had the strongest association with early menarche when each adversity was examined in a separate model. In models adjusting for co-occurrence among the five adversities most strongly associated with early menarche, only childhood sexual abuse remained associated with early menarche at a statistically significant level. Absence of biological father during childhood, theorized to affect early menarche due to early triggering of sexual development, was not associated with early menarche in this study.

These results are consistent with prior studies in finding that stressors in childhood may have biological influences on endocrine development resulting in early menarche, a key developmental milestone with important social and biological consequences that extend

Table 3 Adjusted associations of number of adversities and individual types of adversities with early menarche

\begin{tabular}{|c|c|c|c|c|c|}
\hline & & \multicolumn{2}{|c|}{ Model 1} & \multicolumn{2}{|c|}{ Model 2} \\
\hline & & Adjusted odds ratio & $95 \% \mathrm{Cl}$ & Adjusted odds ratio & $95 \% \mathrm{Cl}$ \\
\hline \multirow[t]{5}{*}{ Age (years) } & $18-27$ & 1 & & 1 & \\
\hline & $28-37$ & 1.22 & $(0.90,1.66)$ & 1.23 & $(0.90,1.67)$ \\
\hline & $38-47$ & 0.94 & $(0.67,1.32)$ & 0.94 & $(0.67,1.33)$ \\
\hline & $48-58$ & 1.13 & $(0.84,1.54)$ & 1.14 & $(0.83,1.56)$ \\
\hline & $59-98$ & 0.97 & $(0.68,1.39)$ & 0.98 & $(0.68,1.41)$ \\
\hline \multirow[t]{4}{*}{ Ethnicity } & White & 1 & & 1 & \\
\hline & Hispanic & 1.49 & $(1.02,2.15)$ & 1.47 & $(1.00,2.15)$ \\
\hline & Black & 1.45 & $(0.94,2.22)$ & 1.44 & $(0.94,2.21)$ \\
\hline & Other & 0.61 & $(0.33,1.16)$ & 0.61 & $(0.31,1.20)$ \\
\hline BMI (standardized) & & 1.22 & $(1.12,1.33)$ & 1.22 & $(1.12,1.33)$ \\
\hline Number of adversities & & 1.26 & $(1.14,1.39)$ & - & - \\
\hline \multirow[t]{5}{*}{ Type of adversities } & Parent substance abuse & - & - & 1.06 & $(0.74,1.50)$ \\
\hline & Parent mental illness & - & - & 1.18 & $(0.91,1.55)$ \\
\hline & Family violence & - & - & 1.14 & $(0.87,1.50)$ \\
\hline & Physical abuse & - & - & 1.35 & $(0.98,1.88)$ \\
\hline & Sexual abuse & - & - & 1.77 & $(1.21,2.60)$ \\
\hline
\end{tabular}

Model 1: Number (count) of adversities as a continuous predictor with statistical adjustment for age, ethnicity, and BMI (i.e. ORs in model 1 are adjusted for all variables in the first column).

Model 2: Main effects of the five childhood adversities with the strongest associations with early menarche with statistical adjustment for age, ethnicity, and BMI (i.e. ORs in model 2 are adjusted for all variables in the second column). 
across adulthood. However, the evidence regarding specific mechanisms is mixed. Theories related to paternal investment, suggested by Draper and Harpending [55] as well as Belsky [56], hypothesizing that the absence of the biological father during childhood would trigger early sexual development have received some support. However, in this study, absence of the biological father was not associated with early menarche. The current findings are congruent with those of Ellis [36,37], in that the impact of early father absence on early menarche does not exist independent of other moderating factors in the environment. At the same time, the finding that sexual abuse prior to menarche is the strongest predictor of early menarche may implicate a related pathway. Several previous studies have also found that childhood sexual abuse is associated with early menarche $[19,28,30,31,57,58]$, including a recent study showing links between childhood sexual abuse and early menarche in a large sample of African-American women [29] as well as a study suggesting a dose-response relationship between severity of sexual abuse and early menarche [34]. None of these studies including the current study, however, has included information on timing of pre-menarchal development of secondary sexual characteristics, which may contribute to increased risk for sexual abuse. Similarly, while beyond the scope of this study, examination of the differential impact of childhood adversities such as absence of biological father at different developmental stages (i.e., early childhood versus early adolescence) would help elucidate the specific pathways for the influence of childhood adversities on pubertal development.

This study has several limitations. Most importantly, we rely on retrospective reporting of both childhood adversities and age of menarche. A large literature examining associations of recalled childhood adversities with health outcomes has proven valuable despite the known limitation of retrospective assessment [59]. However, it is possible that certain adversities such as sexual abuse will be recalled more readily than others. Previous studies on recalled age of menarche found participant recall to be accurate within one year in $90 \%$ of cases between the teenage years and 30 years after the event [60,61]. As some of the study participants were in their 50s and 60s, it is possible that there is more recall bias with underreporting of childhood adversities and inaccurate timing of menarche among the older birth cohorts. In addition, data on BMI were available only from the time of interview as an adult, not from the period preceding menarche. This limitation is partially addressed by including participants' BMI at the time of the interview in final analyses, as adult obesity and childhood obesity are highly correlated [62,63]. However, the self-reported adult height and weight to calculate BMI add an additional potential inaccuracy to these data (i.e., BMI is likely to be underestimated). Finally, information on the exact timing was not available for all adversities considered in the analysis, in particular for absence of biological father. It is possible in these cases that the adversity occurred after menarche and was misclassified in this study. Definitions have been constructed in these cases to minimize the possible impact of misclassification. It is unlikely that the remaining misclassification would result in bias in any particular direction.

Interpretation of the findings should also consider the absence of information on maternal age at menarche in this study and in most other studies of this topic. As noted by Moffitt and colleagues [24], early menarche may lead to early sexual debut and early marriage. Given that early age at marriage is a strong predictor of divorce, children of mothers with early age at marriage may be more likely to grow up in disadvantaged settings, in which they are at risk for a wide variety of childhood adversities. In this scenario, genetic transmission of age at menarche may underlie the observed associations between childhood adversities and early menarche. A study by Wise and colleagues included statistical control for maternal age at marriage, which would adjust in part for this pathway [29]. In that study, sexual abuse and physical abuse remained significantly associated with early menarche, although with associations of lesser magnitude than identified in this study.

\section{Conclusions}

These findings are consistent with the theory that adverse family environments have physiologic effects on endocrine development and, through these effects, may impact mental and physical health outcomes in adulthood. Childhood sexual abuse is the adversity most strongly associated with early menarche. However, because of the complex way that childhood adversities cluster within families, the more generalized influence of highly dysfunctional family environments cannot be ruled out. More detailed studies that address gene-environment correlations as well as the possibility of confounding by pre-menarchal development are needed to advance towards more solid evidence that the associations observed here reflect a distinct bio-social etiology.

\section{Abbreviation \\ NCS-R: National Comorbidity Survey Replication.}

\section{Competing interests}

The authors declared that they have no competing interests.

\section{Authors' contributions}

$\mathrm{KH}$ conceptualized the study, conducted the literature review, participated in the design and analyses, drafted the initial manuscript, and approved the final manuscript as submitted. HLM participated in review of the analyses, critically reviewed and revised the manuscript, and approved the final manuscript as submitted. EM conceptualized and designed the study, reviewed and revised the manuscript, and approved the final manuscript as 
submitted. DS assisted in conceptualizing and designing the study, reviewed and revised the manuscript, and approved the final manuscript as submitted. NS participated in the design of the study, carried out the analyses, reviewed and revised the manuscript, and approved the final manuscript as submitted. $J A B$ designed the study, directed the analyses, reviewed and revised the manuscript, and approved the final manuscript as submitted. All authors read and approved the final manuscript.

\section{Acknowledgments}

This research was supported by a Children's Miracle Network Grant. We appreciate the additional support from the Department of Pediatrics at the University of California Davis. We also acknowledge the Honorable Donna Petre for her encouragement to examine the role of absent biological father on development.

\section{Author details}

'University of Wisconsin School of Medicine and Public Health, 600 Highland Avenue, Madison, WI 53792-4108, USA. ${ }^{2}$ University of Pittsburgh School of Medicine, 3420 Fifth Avenue, Pittsburgh, PA 15213, USA. ${ }^{3}$ Children's Hospital of Pittsburgh, University of Pittsburgh Medical Center, 3420 Fifth Avenue, Pittsburgh, PA 15213, USA. ${ }^{4}$ University of California Davis, 2516 Stockton Blvd, Sacramento, CA 95817, USA. ${ }^{5}$ University of California Davis, 1616 DaVinci Court, Davis, CA 95618, USA. ${ }^{6}$ RAND Corporation, 4570 Fifth Avenue, Suite 600,

Pittsburgh, PA 15213, USA

Received: 11 December 2013 Accepted: 20 May 2014

Published: 15 July 2014

\section{References}

1. Thomas F, Renaud F, Benefice R, de Meeus T, Guegan JF: International variability of ages at menarche and menopause: patterns and main determinants. Hum Biol 2001, 73(2):271-290.

2. Ong KK, Ahmed ML, Dunger DB: Lessons from large population studies on timing and tempo of puberty (secular trends and relation to body size): the European trend. Mol Cell Endocrinol 2006, 254-255:8-12. Epub 2006 Jun 6.

3. Melmed S, Polonsky KS, Larsen PR, Kronenberg HM: Williams Textbook of Endocrinology. 12th edition. Philadelphia, PA: Saunders and Elsevier Inc; 2011.

4. Jacobsen BK, Oda K, Knutsen SF, Fraser GE: Age at menarche, total mortality and mortality from ischaemic heart disease and stroke: the Adventist Health Study, 1976-88. Int J Epidemiol 2009, 38(1):245-252.

5. Lakshman R, Forouhi NG, Sharp SJ, Luben R, Bingham SA, Khaw KT, Wareham NJ, Ong KK: Early age at menarche associated with cardiovascular disease and mortality. J Clin Endocrinol Metab 2009, 94(12):4953-4960.

6. Remsberg KE, Demerath EW, Schubert CM, Chumlea WC, Sun SS, Siervogel RM: Early menarche and the development of cardiovascular disease risk factors in adolescent girls: the Fels Longitudinal Study. J Clin Endocrinol Metab 2005, 90(5):2718-2724. Epub 2005 Feb 22.

7. Black SR, Klein DN: Early Menarcheal Age and Risk for Later Depressive Symptomatology: The Role of Childhood Depressive Symptoms. J Youth Adolesc 2012, 41(9):1142-50.

8. Downing J, Bellis MA: Early pubertal onset and its relationship with sexual risk taking, substance use and anti-social behaviour: a preliminary cross-sectional study. BMC Public Health 2009, 9:446.

9. Belsky J, Steinberg L, Houts RM, Halpern-Felsher BL, NICHD Early Child Care Research Network: The development of reproductive strategy in females: early maternal harshness - earlier menarche - increased sexual risk taking. Dev Psychol 2010, 46(1):120-128.

10. Rosell M, Appleby P, Key T: Height, age at menarche, body weight and body mass index in life-long vegetarians. Public Health Nutr 2005, 8(7):870-875.

11. Lee JM, Appugliese D, Kaciroti N, Corwyn RF, Bradley RH, Lumeng JC: Weight status in young girls and the onset of puberty. Pediatrics 2007 119(3):e624-e630.

12. Ahmed ML, Ong KK, Dunger DB: Childhood obesity and the timing of puberty. Trends Endocrinol Metab 2009, 20(5):237-242. Epub 2009 Jun 21.

13. Elks CE, Ong KK: Whole genome associated studies for age at menarche. Brief Funct Genomics 2011, 10(2):91-97.
14. Manuck SB, Craig AE, Flory JD, Halder I, Ferrell RE: Reported early family environment covaries with menarcheal age as a function of polymorphic variation in estrogen receptor-alpha. Dev Psychopathol 2011, 23(1):69-83.

15. Umlawska W, Krzyzanowska M: Puberty in certain chronic illness. Pediatr Endocrinol Diabetes Metab 2009, 15(3):216-218.

16. Anderson SE, Dallal GE, Must A: Relative weight and race influence average age at menarche: results from two nationally representative surveys of US girls studied 25 years apart. Pediatrics 2003, 111(4 Pt 1):844-850.

17. Braithwaite D, Moore DH, Lustig RH, Epel ES, Ong KK, Rehkopf DH, Wang MC, Miller SM, Hiatt RA: Socioeconomic status in relation to early menarche among black and white girls. Cancer Causes Control 2009, 20(5):713-720. Epub 2008 Dec 25.

18. Freedman DS, Khan LK, Serdula MK, Dietz WH, Srinivasan SR, Berenson GS: Relation of age at menarche to race, time period, and anthropometric dimensions: the Bogalusa Heart Study. Pediatrics 2002, 110(4):e43.

19. Vigil JM, Geary DC, Byrd-Craven J: A life history assessment of early childhood sexual abuse in women. Dev Psychol 2005, 41(3):553-561.

20. Boynton-Jarrett R, Ryan LM, Berkman LF, Wright RJ: Cumulative violence exposure and self-rated health: longitudinal study of adolescents in the United States. Pediatrics 2008, 122(5):961-970.

21. Greenfield EA: Child abuse as a life-course social determinant of adult health. Maturitas 2010, 66(1):51-55. Epub 2010 Mar 6.

22. Boynton-Jarrett R, Rich-Edwards JW, Jun HJ, Hibert EN, Wright RJ: Abuse in childhood and risk of uterine leiomyoma: the role of emotional support in biologic resilience. Epidemiology 2011, 22(1):6-14.

23. Boynton-Jarrett R, Rosenberg L, Palmer JR, Boggs DA, Wise LA: Child and Adolescent Abuse in Relation to Obesity in Adulthood: The Black Women's Health Study. Pediatrics 2012, 130(2):245-253.

24. Moffitt TE, Caspi A, Belsky J, Silva PA: Childhood experience and the onset of menarche: a test of a sociobiological model. Child Dev 1992, 63(1):47-58

25. Wierson M, Long PJ, Forehand RL: Toward a new understanding of early menarche: the role of environmental stress in pubertal timing. Adolescence 1993, 28(112):913-924.

26. Belsky J, Steinberg LD, Houts RM, Friedman SL, DeHart G, Cauffman E, Roisman GI, Halpern-Felsher BL, Susman E, NICHD Early Child Care Research Network: Family rearing antecedents of pubertal timing. Child Dev 2007, 78(4):1302-1321.

27. Herman-Giddens ME, Sandler AD, Friedman NE: Sexual precocity in girls. An association with sexual abuse? Am J Dis Child 1988, 142(4):431-433.

28. Romans SE, Martin JM, Gendall K, Herbison GP: Age of menarche: the role of some psychosocial factors. Psychol Med 2003, 33(5):933-939.

29. Wise LA, Palmer JR, Rothman EF, Rosenberg L: Childhood abuse and early menarche: findings from the black women's health study. Am J Public Health 2009, 99(Suppl 2):S460-S466. Epub 2009 May 14.

30. Zabin LS, Emerson MR, Rowland DL: Childhood sexual abuse and early menarche: the direction of their relationship and its implications. $J$ Adolesc Health 2005, 36(5):393-400.

31. Brown J, Cohen P, Chen H, Smailes E, Johnson JG: Sexual trajectories of abused and neglected youths. J Dev Behav Pediatr 2004, 25(2):77-82.

32. Turner $P$, Runtz $M$, Galambos N: Sexual abuse, pubertal timing, and subjective age in adolescent girls: A research note. J Reprod Infant Psychol 1993, 17:111-118.

33. Mendle J, Leve LD, Van Ryzin M, Natsuaki MN, Ge X: Associations between early life stress, child maltreatment, and pubertal development among girls in foster care. J Res Adolesc 2011, 21(4):871-880.

34. Boynton-Jarrett R, Wright RJ, Putnam FW, Hibert EL, Michels KB, Forman MR, Rich-Edwards J: Childhood abuse and age at menarche. J Adolesc Health 2013, 52(2):241-247.

35. Campbell BC, Udry JR: Stress and age at menarche of mothers and daughters. J Biosoc Sci 1995, 27(2):127-134.

36. Deardorff J, Ekwaru JP, Kushi LH, Ellis BJ, Greenspan LC, Mirabedi A, Landaverde EG, Hiatt RA: Father absence, body mass index, and pubertal timing in girls: differential effects by family income and ethnicity. $J$ Adolesc Health 2011, 48(5):441-447.

37. Tither JM, Ellis BJ: Impact of fathers on daughters' age at menarche: a genetically and environmentally controlled sibling study. Dev Psychol 2008, 44(5):1409-1420.

38. Ellis BJ, Garber J: Psychosocial antecedents of variation in girls' pubertal timing: maternal depression, stepfather presence, and marital and family stress. Child Dev 2000, 71(2):485-501. 
39. Bogaert AF: Age at puberty and father absence in a national probability sample. J Adolesc 2005, 28(4):541-546. Epub 2005 Jan 20.

40. Mendle J, Turkheimer E, D'Onofrio BM, Lynch SK, Emery RE, Slutske WS, Martin NG: Family structure and age at menarche: a children-of-twins approach. Dev Psychol 2006, 42(3):533-542.

41. Bogaert AF: Menarche and father absence in a national probability sample. J Biosoc Sci 2008, 40(4):623-636. Epub 2007 Aug 30.

42. Lohr S: Sampling: Design and Analysis. Boston: Brooks/Cole; 2010

43. Kessler RC, Merikangas KR: The National Comorbidity Survey Replication (NCS-R): background and aims. Int J Methods Psychiatr Res 2004, 13(2):60-68

44. Kessler RC, Berglund P, Chiu WT, Demler O, Heeringa S, Hiripi E, Jin R, Pennell BE, Walters EE, Zaslavsky A, Zheng H: The US National Comorbidity Survey Replication (NCS-R): design and field procedures. Int J Methods Psychiatr Res 2004, 13(2):69-92X.

45. Breslau N, Novak SP, Kessler RC: Daily smoking and the subsequent onset of psychiatric disorders. Psychol Med 2004, 34(2):323-333.

46. Chumlea WC, Schubert CM, Roche AF, Kulin HE, Lee PA, Himes JH, Sun SS: Age at menarche and racial comparisons in US girls. Pediatrics 2003, 111(1):110-113.

47. Straus MA, Douglas EM: A short form of the Revised Conflict Tactics Scales, and typologies for severity and mutuality. Violence Vict 2004 19(5):507-520

48. Molnar BE, Buka SL, Kessler RC: Child sexual abuse and subsequent psychopathology: results from the National Comorbidity Survey. Am Public Health 2001, 91(5):753-760.

49. Courtney ME, Piliavin I, Grogan-Kaylor A, Nesmith A: Foster youth transitions to adulthood: a longitudinal view of youth leaving care. Child Welfare 2001, 80(6):685-717.

50. Kendler KS, Silberg JL, Neale MC, Kessler RC, Heath AC, Eaves LJ: The family history method: whose psychiatric history is measured? Am J Psychiatry 1991, 148(11):1501-1504

51. Andreasen NC, Endicott J, Spitzer RL, Winokur G: The family history method using diagnostic criteria. Reliability and validity. Arch Gen Psychiatry 1977, 34(10):1229-1235.

52. Herman KM, Craig CL, Gauvin L, Katzmarzyk PT: Tracking of obesity and physical activity from childhood to adulthood: the Physical Activity Longitudinal Study. Int J Pediatr Obes 2009, 4(4):281-288.

53. Deshmukh-Taskar P, Nicklas TA, Morales M, Yang SJ, Zakeri I, Berenson GS: Tracking of overweight status from childhood to young adulthood: the Bogalusa Heart Study. Eur J Clin Nutr 2006, 60(1):48-57.

54. Research Triangle Institute: SUDAAN Language Manual, Release 10.0. Research Triangle Park, NC: Research Triangle Institute; 2008.

55. Draper $\mathrm{P}$, Harpending $\mathrm{H}$ : Father absence and reproductive strategy: An evolutionary perspective. J Anthropol Res 1982, 38:255-273.

56. Belsky J, Steinberg L, Draper P: Childhood experience, interpersonal development, and reproductive strategy: and evolutionary theory of socialization. Child Dev 1991, 62(4):647-670

57. Jorm AF, Christensen H, Rodgers B, Jacomb PA, Easteal S: Association of adverse childhood experiences, age of menarche, and adult reproductive behavior: does the androgen receptor gene play a role? Am J Med Genet B Neuropsychiatr Genet 2004, 125B(1):105-111.

58. Hulanicka B, Gronkiewicz L, Koniarek J: Effect of familial distress on growth and maturation of girls: a longitudinal study. Am J Hum Biol 2001, 13(6):771-776

59. Felitti VJ, Anda RF, Nordenberg D, Williamson DF, Spitz AM, Edwards V, Koss MP, Marks JS: Relationship of childhood abuse and household dysfunction to many of the leading causes of death in adults. The Adverse Childhood Experiences (ACE) Study. Am J Prev Med 1998, 14(4):245-258

60. Damon A, Bajema CJ: Age at menarche: Accuracy of recall after thirtynine years. Hum Biol 1974, 46(3):381-384.

61. Zacharias L, Wurtman RJ, Schatzoff M: Sexual maturation in contemporary American girls. Am J Obstet Gynecol 1970, 108(5):833-846.

62. Wang Y, Zhang Q: Are American children and adolescents of low socioeconomic status at increased risk of obesity? Changes in the association between overweight and family income between 1971 and 2002. Am J Clin Nutr 2006, 84(4):707-716.

63. Elks CE, Loos RJ, Hardy R, Wills AK, Wong A, Wareham NJ, Kuh D, Ong KK: Adult obesity susceptibility variants are associated with greater childhood weight gain and a faster tempo of growth: the 1946 British Birth Cohort Study. Am J Clin Nutr 2012, 95(5):1150-1156.

doi:10.1186/1687-9856-2014-14

Cite this article as: Henrichs et al:: Early menarche and childhood adversities in a nationally representative sample. International Journal of Pediatric Endocrinology 2014 2014:14.

\section{Submit your next manuscript to BioMed Central and take full advantage of:}

- Convenient online submission

- Thorough peer review

- No space constraints or color figure charges

- Immediate publication on acceptance

- Inclusion in PubMed, CAS, Scopus and Google Scholar

- Research which is freely available for redistribution

Submit your manuscript at www.biomedcentral.com/submit
C) BioMed Central 